\title{
Contribution of enriched wheat flour and flour products to iron requirements in children aged 6 months to 7 years
}

\author{
Agustina Malpeli, B.S. ${ }^{a}$, Ana Varea, Biochemist ${ }^{a}$, Vania Vargas, B.S. ${ }^{a}$, \\ Hanna Fritz Heck, B.S. ${ }^{a}$, Victoria Fasano, B.S. ${ }^{a}$, Daniel Asens, B.S. ${ }^{b}$ and \\ Enrique Martins, Biochemist ${ }^{a}$
}

\begin{abstract}
Introduction. Wheat flour enrichment is a public health strategy recommended to prevent micronutrient deficiencies, including iron deficiency. The objective of this study was to determine iron content in enriched wheat flour and flour products and their contribution to nutritional recommendations for children.

Population and methods. Observational, analytical, cross-sectional study based on the total diet study method. Enriched wheat flour (as per Law no. 25630) and the most frequently consumed flour products were analyzed. Products were selected using a questionnaire on the frequency of food intake and a 24-hour recall interview with the parents of children aged 6 months to 7 years. Food iron levels were determined based on atomic absorption spectrometry and their contribution to the estimated average requirement was assessed.

Results. Enriched flour and flour products showed the expected iron amount, except for French bread and breadcrumbs. The contribution of studied products to iron requirements was $7 \%$ in children aged 6 months to 1 year, $81 \%$ in those aged 1-3 years, and $45 \%$ in those older than 4 years.

Conclusions. Except for French bread and breadcrumbs, studied flour and flour products showed the expected enrichment level. The consumption of this type of food does not provide significant amounts of iron to infants, but it does to children older than 1 year.
\end{abstract}

Key words: child, wheat flour, fortified food, iron.

http: / / dx.doi.org/10.5546/ aap.2021.eng.304

To cite: Malpeli A, Varea A, Vargas V, Fritz Heck H, et al. Contribution of enriched wheat flour and flour products to iron requirements in children aged 6 months to 7 years. Arch Argent Pediatr 2021;119(5):304-309.

\section{INTRODUCTION}

Food enrichment is a public health strategy recommended to prevent micronutrient deficiencies, ${ }^{1,2}$ including iron deficiency. Iron deficiency is the most common nutritional deficit and the main cause of anemia, which affects more than $40 \%$ of preschool children worldwide. In Argentina, anemia is prevalent in children younger than 2 years, but it also affects children younger than 6 years. ${ }^{3-5}$

Specifically, it has been demonstrated that wheat flour enrichment with iron is an adequate vehicle in countries where flour is regularly consumed. More than 80 countries have passed some type of legislation aimed at wheat flour fortification with iron. ${ }^{1,7}$ In 2003, Argentina regulated Law no. 25630, which establishes that any wheat flour marketed across the country should be enriched with iron $(30 \mathrm{mg} /$ $\mathrm{kg})$, folic acid $(2.2 \mathrm{mg} / \mathrm{kg})$, thiamin $(6.3 \mathrm{mg} / \mathrm{kg})$, riboflavin $(1.3 \mathrm{mg} / \mathrm{kg})$, and niacin $(13 \mathrm{mg} / \mathrm{kg}) .{ }^{8}$ Since the regulation of the law, the first analytic control of adherence to the law was performed in 2008 and the most recent one, in 2018. The report indicated that adherence to the law was consistently about $80 \%$ for all analyzed determinations. ${ }^{9}$ However, average iron levels in studied foods or the contribution to the most vulnerable populations were not reported.

The assessment of the universal impact of food on anemia is intricate, because it may take place together with other strategies with a common objective, such as prophylactic ferrous sulfate supplementation in children 
and the consumption of specific fortified foods in some vulnerable groups. ${ }^{10,11}$ The investigation of the contribution from different iron sources to diet in these groups may provide important information that could help to implement or modify public policies. In line with this, the study by Zapata, also published in this journal, concluded that enriched flour and flour products provide an adequate iron intake to the population assessed in the Survey on Nutritional Food Intake of the Autonomous City of Buenos Aires (Encuesta Alimentaria Nutricional de la Ciudad de Buenos Aires, EAN-CABA). However, the assessment was made based on theoretical iron content. ${ }^{11}$

The objective of this study was to determine iron content in enriched wheat flour and flour products and their contribution to nutritional recommendations for children aged 6 months to 7 years who are seen in the public health system of La Plata.

\section{POPULATION AND METHODS}

The study was conducted between June 2018 and June 2019 at the Pediatric Research and Development Institute (Instituto de Desarrollo e Investigaciones Pediátricas, IDIP) "Prof. Dr. Fernando Viteri" of Hospital de Niños de La Plata, Scientific Research Commission (Comisión de Investigaciones Cientificas, CIC), Ministry of Health (MoH), Province of Buenos Aires. This was an observational, exploratory, analytical, cross-sectional study.

The parents or legal guardians of children who attended the pediatric offices of the IDIP for their health checkup were invited to participate. The sample was selected by convenience, in a non-probabilistic fashion. Children who were on a special diet for a medical condition and those whose parents or legal guardians refused to participate in the study were excluded.

During the interview, in addition to completing the survey on food intake, address and outcome measures to assess basic needs ${ }^{12}$ and level of maternal education were recorded.

The methodology selected for this study was based on total diet study-like investigations, which analyze only a group of foods of interest, in this case, enriched foods. ${ }^{13}$ below.

The study was carried out in stages, as detailed

\section{Stage 1. Administration and analysis of the survey on food intake}

A survey on frequency of food intake was administered to the parents or legal guardians of children in relation to wheat flour and flour products consumption by children in the past month. The brand of wheat flour and all flour products also encompassed by the law and the place of purchase were also studied. Foods and brands to be included were selected based on prior surveys. ${ }^{14}$ The list included wheat flour and products made from enriched wheat flour, such as bread and cookies. Noodles and spaghetti were not included in the list because the brands mentioned by the study population are made with wheat semolina, which is not within the bounds of the law. Fresh pasta was also not included because they were not consumed by the study population during the study period.

To estimate serving sizes (median consumption), a 24-hour recall interview was done using visual aids and replicas of food in order to estimate amounts. Food consumption at school in children who attended school was not taken into consideration because it was not possible to know for certain the amounts consumed. Surveys were administered and analyzed by providers who had a B.S. in Nutrition. To determine the analytical iron content, a total of 42 samples of the following foods were selected: wheat flour, crackers, sweet cookies, filled biscuits, French bread, ladyfingers, pastry, cookie sandwich, sponge cake mix, sliced bread, and breadcrumbs (commercial and bulk).

\section{Stage 2. Purchase and preparation of selected foods}

Selected foods were acquired from different stores according to the answers provided in the survey. Packaged foods of the brands most commonly mentioned by survey respondents were included, whereas bulk products were purchased from 4 different stores.

The following samples were collected: wheat flour (5), French bread (bulk) (4), pastry (bulk) (4: 2 croissants, 1 filled with dulce de leche, and 1 filled with custard), crackers (4), sweet cookies (including ladyfingers) (8), filled biscuits (4), cookie sandwich (2), sliced bread (2), sponge cake mix (1), commercial breadcrumbs (4), and bulk breadcrumbs (4) (from the stores where participants bought breaded beef).

\section{Stage 3. Iron determination}

Approximately $0.5 \mathrm{~g}$ of each composite sample was weighed. Heat and pressure digestion was done using a CEM MDS-2000 ${ }^{\circledR}$ microwave 
digestion system, and $8 \mathrm{~mL}$ of concentrated nitric acid and $1 \mathrm{~mL}$ of hydrogen peroxide were added to each sample. Lastly, samples were brought to a $50 \mathrm{~mL}$ volume with double-distilled water and stored at $-20^{\circ} \mathrm{C}$ in plastic containers until analysis. This procedure was performed at Instituto Biológico "Dr. Tomás Perón".

At the IDIP, iron levels were measured in duplicate using a Varian AA240FS ${ }^{\circledast}$ flame atomic absorption spectrometer, with a $248.3 \mathrm{~nm}$ wavelength. A calibration curve as measured by a $\mathrm{NIST}^{\circledR}$ traceable standard was prepared (Certipur Iron standard solution, Merck). Reagent and container blanks were determined to rule out their potential contamination.

\section{Stage 4. Analysis of results}

Results of iron level determination in studied foods were compared to the theoretical iron content values in flour and flour products as described in the Food Analysis and Registration System (Sistema de Análisis y Registro de Alimentos, SARA). ${ }^{15}$

Iron levels were measured in all foods included in the survey, regardless of the number of participants that consumed them. To assess flour enrichment's contribution to iron requirement, food intake was arranged top-down and only foods that covered $90 \%$ of the daily intake were taken into consideration. For this reason, sliced bread and commercial breadcrumbs were excluded.

The estimated average requirement (EAR) was described by age category: 6-12 months $(6.9 \mathrm{mg} /$ day), children aged $1-3$ years ( $3 \mathrm{mg} /$ day), and children aged $4-7$ years $\left(4.1 \mathrm{mg} /\right.$ day). ${ }^{16}$

The following outcome measures were defined:
- Sample's iron content: iron level in flour or flour products expressed as $\mathrm{mg} / \mathrm{kg}$ of food.

- Daily intake of flour and flour products: median flour and flour products daily intake.

- Iron intake from flour and flour products: it was estimated based on the 2 preceding outcome measures.

- Contribution of iron in flour and flour products to recommendations: percentage of iron EAR coverage by age group. ${ }^{16}$

The SPSS $25^{\circledR}$ software was used for statistical data analysis.

\section{Ethical aspects}

The protocol was approved by the Institutional Research Protocol Review Committee (Comité Institucional de Revisión de Protocolos de Investigación, CIRPI). Personal data were collected according to article 3 of National Law No. 25326 for Personal Data Protection. In all cases, a written authorization in the form of a free, informed, and express consent was obtained from parents or legal guardians.

\section{RESULTS}

A total of 120 surveys on food intake were completed. Age distribution was as follows: 20 children were aged 6 months to 1 year; 52 were 1-3 years old; and 48, 4-7 years old. A total of $58.2 \%$ were males.

The most represented area of residence of participants (59\%) was the south-west area of La Plata. Unmet basic needs were observed in $36 \%$ of households; more than $80 \%$ had substandard housing conditions; and $10 \%$ of mothers did not complete primary school.

Table 1 shows the theoretical content (SARA tables) and measured iron content in enriched

TABLE 1. Theoretical and measured iron contents in all analyzed foods consumed by children aged 6 months to 7 years

\begin{tabular}{lcc}
\hline Food & $\begin{array}{c}\text { Theoretical iron content } \\
(\mathbf{m g} / \mathbf{k g})^{\mathbf{1 3}}\end{array}$ & $\begin{array}{c}\text { Measured iron content } \\
(\mathbf{m g} / \mathbf{k g})\end{array}$ \\
\hline Wheat flour & 45.0 & 43 \\
French bread & 33.0 & 23.6 \\
Pastry & 21.9 & 23.6 \\
Crackers & 34.3 & 35.1 \\
Sweet cookies & 22.5 & 22.4 \\
Filled biscuits & 32.1 & 37.8 \\
Ladyfingers & 22.8 & 21.9 \\
Sponge cake mix & $\mathrm{ND}$ & 34.0 \\
Cookie sandwich & 21.7 & 22.4 \\
Sliced bread & 31.8 & 20.3 \\
Commercial breadcrumbs & 77.0 & 44.4 \\
Bulk breadcrumbs & $\mathrm{ND}$ & 30.9 \\
\hline
\end{tabular}

ND: no data. 
flour and flour products selected based on the survey on food intake. Iron levels measured in the samples of French bread, sliced bread, and breadcrumbs (both commercial and bulk) were below the theoretical values.

Table 2 shows the consumption of these foods, described as median, iron intake ( $\mathrm{mg} /$ day), and their contribution to iron requirements. These products cover a low percentage of the EAR in the group of children aged 6 months to 1 year $(7 \%)$, but its coverage is higher among older children: $81 \%$ in the group aged $1-3$ years and $45 \%$ in children older than 4 years.

\section{DISCUSSION}

The analysis of iron determination shows that wheat flour samples have the enrichment levels required by law. The remaining foods (flour products) have the estimated amounts indicated in the chemical composition tables most commonly used in Argentina (SARA), except for French bread, sliced bread, and breadcrumbs. The contribution to iron requirements is low in infants younger than 1 year and higher in the remaining age groups studied; the group of children aged 1-3 years showed the greatest contribution from these foods.

In the children assessed in this study, the average bread consumption was much lower than that reported in the First National Survey on Nutrition and Health (Encuesta Nacional de Nutrición y Salud, ENNyS I), where the median bread intake was $35 \mathrm{~g} /$ day in children younger than 2 years and $70 \mathrm{~g} /$ day in those aged $2-5$ years. ${ }^{17}$

Many countries have passed laws establishing wheat flour enrichment with iron, but just a few carried out laboratory studies and published the results. ${ }^{7}$ Whereas Chile, Colombia, Iran, and Uruguay adhere to the law, Cameroon failed to reach the iron levels required by law.,18-21

The study by Zapata et al. mentioned above analyzed the information from the First Survey on Nutritional Food Intake of the Autonomous City of Buenos Aires and showed a greater contribution of iron from these foods than our

TABLE 2. Amount of food consumed (median consumption), iron intake from analyzed foods (mg/day), and contribution to iron requirements (\%) by age group

\begin{tabular}{|c|c|c|c|}
\hline Food & $\begin{array}{l}\text { Estimated daily intake } \\
\text { (median, g/day) }\end{array}$ & $\begin{array}{l}\text { Amount of iron intake } \\
\text { (mg/day) }\end{array}$ & $\begin{array}{c}\text { Contribution to iron } \\
\text { requirements }(\%)\end{array}$ \\
\hline \multicolumn{4}{|c|}{ Infants aged 6-12 months } \\
\hline French bread & 8 & 0.19 & 3 \\
\hline Ladyfingers & 5 & 0.11 & 2 \\
\hline Crackers & 4 & 0.09 & 1 \\
\hline Sweet cookies & 2 & 0.07 & 1 \\
\hline Total & & 0.46 & 7 \\
\hline \multicolumn{4}{|l|}{ Children aged 1-3 years } \\
\hline French bread & 24 & 0.56 & 19 \\
\hline Crackers & 13 & 0.45 & 15 \\
\hline Sweet cookies & 14 & 0.32 & 11 \\
\hline Sponge cake mix & 9 & 0.29 & 10 \\
\hline Breadcrumbs (bulk) & 5 & 0.15 & 5 \\
\hline Wheat flour & 7 & 0.32 & 11 \\
\hline Filled biscuits & 3 & 0.12 & 3 \\
\hline Pastry & 3 & 0.08 & 3 \\
\hline Ladyfingers & 3 & 0.07 & 2 \\
\hline Cookie sandwich & 2 & 0.06 & 2 \\
\hline Total & & 2.42 & 81 \\
\hline \multicolumn{4}{|l|}{ Children aged 4-7 years } \\
\hline French bread & 13 & 0.31 & 8 \\
\hline Sponge cake mix & 13 & 0.45 & 11 \\
\hline Breadcrumbs (bulk) & 9 & 0.27 & 7 \\
\hline Crackers & 7 & 0.23 & 6 \\
\hline Sweet cookies & 8 & 0.18 & 4 \\
\hline Wheat flour & 4 & 0.17 & 4 \\
\hline Pastry & 5 & 0.13 & 3 \\
\hline Filled biscuits & 2 & 0.09 & 2 \\
\hline Total & & 1.83 & 45 \\
\hline
\end{tabular}


study. ${ }^{11}$ This may be because, in our study, French bread had a lower iron level than that estimated in the tables, age groups are not similar, and the amount of food consumed may vary. In addition, there may be differences in the socioeconomic characteristics of compared populations and, therefore, in their diet.

Iron requirements in children up to 6 months old are covered by breast milk; after this age, they need iron supplementation and the introduction of iron-rich foods to avoid iron deficiency. ${ }^{10}$ However, enriched wheat flour and flour products are not a source of iron in this age group. ${ }^{2}$ In older children, the growth rate decreases and so do their iron requirements. As of 1 year old, children are incorporated into the family diet and studied foods cover a greater proportion of iron requirements. ${ }^{4}$

The impact of wheat flour enrichment with iron on the prevalence of anemia has proven to be positive in some studies, $3,5,22,23$ although others have not corroborated such improvement. ${ }^{24,25}$

A study carried out by our task force in $2004^{26}$ in the province of Buenos Aires showed that the prevalence of anemia decreased over 1 year from $55 \%$ to $39 \%$ in children younger than 2 years as a result of the synergistic effect of delivering foods containing micronutrients and the enactment of the law establishing flour enrichment. As described by Hurrell, the greatest impact of flour fortification with iron may be observed in the first year after the strategy implementation. ${ }^{26}$

To our knowledge, this is the first study that measured food iron levels using laboratory techniques. In other similar studies conducted in our region, iron content or contribution was determined based on the estimated theoretical content. ${ }^{11,27}$ It is necessary to perform further analyses about the results observed in relation to French bread and analyze additional bread samples from different regions to draw a more generalized conclusion about whether this wheat flour product contains the adequate iron levels required by law.

This study is the first approach to this subject in the region, and its analysis may continue based on study outcomes. It also has some limitations. Most likely, the study did not include all enriched wheat flour products, but it did consider the foods most commonly consumed by the study population. In the older children group, it is possible that some products they eat at school provide more iron than what is reflected in this study; however, it is very difficult for parents or caregivers to know what their children eat at school. For this reason, we believe some food amounts may be higher and, therefore, make a greater contribution to iron requirements.

\section{CONCLUSION}

The level of wheat flour enrichment corresponds to what has been stipulated in the law. In relation to flour products, French bread, sliced bread, and breadcrumbs have a lower content than the estimated theoretical content. The consumption of this type of food does not provide significant amounts of iron to infants, but it does to children older than 1 year.

\section{REFERENCES}

1. Pachón H, Spohrer R, Mei Z, Serdula MK. Evidence of the effectiveness of flour fortification programs on iron status and anemia: a systematic review. Nutr Rev. 2015; 73(11):780-95.

2. Allen L, De Benoist B, Dary O, Hurrel R (eds). Guidelines on food fortification with micronutrients. Paris: World Health Organization, Food and Agriculture of United Nations, 2006.

3. Field MS, Mithra P, Estevez D, Peña-Rosas JP. Wheat flour fortification with iron for reducing anaemia and improving iron status in populations. Cochrane Database Syst Rev. 2020; 7:CD011302.

4. Pizarro F, Calvo E. El significado a mediano y largo plazo de la deficiencia de hierro y zinc durante los primeros dos años de vida, para asegurar un buen crecimiento temprano. In: Carmuega E, Uauy R, Barker D (eds). Impacto del crecimiento y desarrollo temprano sobrela salud y bienestar de la población: perspectivas y reflexiones desde el Cono Sur. Buenos Aires: Instituto Danone del Cono Sur; 2009. Pages.49-69.

5. González HF. Deficiencia de hierro, la injusta herencia. Arch Argent Pediatr. 2020; 118(3):156-8.

6. Hurrell R, Ranum P, de Pee S, Biebinger R, et al. Revised recommendations for iron fortification of wheat flour and an evaluation of the expected impact of current national wheat flour fortification programs. Food Nutr Bull. 2010; 31(Suppl 1):S7-21.

7. Marks KS, Luthringer CL, Ruth LJ, Rowe LA, et al. Review of grain fortification legislation, standards and monitoring documents. Glob Health Sci Pract. 2018; 6(2):354-69.

8. Ley 25630. Normas para la prevención de las anemias y las malformaciones del tubo neural. Honorable Congreso de la Nación Buenos Aires, Argentina; 22 de agosto de 2002.

9. ANMAT.Informederesultados:programadecumplimiento dela ley nacional $n^{\circ}$ 25630. Buenos Aires, 2018. [Accessed on: March $\left.10^{\text {th }}, 2021\right]$. Availableat:https: / / www.argentina.gob. ar/sites / default/files / anmat_ley_nacional_ndeg_25.630. pdf

10. Comité Nacional de Hematología, Oncología y Medicina Transfusional; Comité Nacional de Nutrición. Deficiencia de hierro y anemia ferropénica. Guía para su prevención, diagnóstico y tratamiento. Arch Argent Pediatr. 2017; 115(Supl 4):S68-82.

11. Zapata ME, Rovirosa A, Carmuega E. Hierro y ácido fólico: natural, enriquecido, fortificado y suplementos. Análisis de las fuentes alimentarias en la Ciudad de Buenos Aires. Arch Argent Pediatr. 2020; 118(3):160-5.

12. Argentina. Instituto Nacional de estadística y censos. Censo Nacional de población, hogares y viviendas 2010: Censo 
del bicentenario: Resultados definitivos, Serie B, Nro. 2. Buenos Aires, INDEC, 2012.

13. World Health Organization; Food and Agriculture Organization; European Food Safety Authority. Towards a harmonised total diet study approach: a guidance document. Roma: EFSA-FAO-WHO; 2011.

14. Martins E, Malpeli A, Asens D, Telese L, et al. Contribución de la dieta a la exposición al plomo de niños de 1 a 7 años en La Plata, Buenos Aires. Arch Argent Pediatr. 2018; 116(1):14-20.

15. Argentina. Ministerio deSalud, Dirección Nacional deSalud Materno Infantil. Software SARA. Sistema de Análisis y Registro de Alimentos, Versión 1.2.22 ed. 2007.

16. Dietary ReferenceIntakes:Estimated AverageRequirements. Food and Nutrition Board. Institute of Medicine National Academies. 1997-2001 - September 2002. [Accessed on: March 10 th, 2021$]$. Available at: www.nal.usda.gov/sites/ default / files / fnic_uploads / recommended_intakes_ individuals.pdf

17. Argentina. Ministerio de Salud. Encuesta Nacional de Nutrición y Salud. Documento de resultados. Buenos Aires: MINSAL;2007. [Accessed on: March 10 $\left.{ }^{\text {th }}, 2021\right]$. Available at: https:/ / bancos.salud.gob.ar/recurso/encuesta-nacionalde-nutricion-y-salud-documento-de-resultados-2007.

18. Russo M, Elichalt M, Vázquez D, Suburú G, el al. Fortificación de harina de trigo con ácido fólico y hierro en Uruguay; implicancias en la nutrición. Rev Chil Nutr. 2014; 41(4):399-403.

19. Chile.DepartamentodeSalud Ambiental,Subdepartamento de Alimentos y Nutrición. Instituto de Salud Pública. Informe programa de fortificación de harinas. Ministerio de Salud; 2011. [Accessed on: March $10^{\text {th }}$, 2021]. Available at: https//static1.squarespace.com/ static/5e1df234eef02705f5446453/t/5f6407471573e80e2b efe3bb/1600390987712/Chile.pdf
20. Buitrago S J, Hurtado LM, Salazar GC. Verificación de la fortificación con hierro en productos de trigo en Bogotá. Vitae. 2012; 19(Supl 1):S457-9.

21. Engle-Stone R, Nankap M, Ndjebayi AO, Allen LH, et al. Iron, zinc, folate and vitamin B-12 status increased among women and children in Yaoundé and Douala, Cameroon, 1 year after introducing fortified wheat flour. J Nutr. 2017; 147(7):1426-36.

22. Wirth JP, Laillou A, Rohner F, Northrop-Clewes CA, et al. Lessons learned from national food fortification projects: Experiences from Morocco, Uzbekistan, and Vietnam. Food Nutr Bull. 2012; 33(Suppl 4):S281-92.

23. Martorell R, Ascencio M, Tacsan L, Alfaro T, el al. Effectiveness evaluation of the food fortification program of Costa Rica: Impact of anemia prevalence and hemoglobin concentrations in women and children. Am J Clin Nutr. 2015; 101(1):210-7.

24. Assunção MC, Santos IS, Barros AJ, Gigante DP, et al. Flour fortification with iron has no impact on anaemia in urban Brazilian children. Public Health Nutr. 2012; 15(10):1796801.

25. Sadighi J, Nedjat S, Rostami R. Systematic review and meta-analysis of the effect of iron-fortified flour on iron status of populations worldwide. Public Health Nutr. 2019; 22(18):3465-84

26. Varea AM, Malpeli A, Etchegoyen G, Vojkovic M, et al. Short-term evaluation of the impact of a food program in the micronutrient nutritional status of Argentinean children under the age of six. Biol Trace Elem Res. 2011; 143(3):133748.

27. Zapata ME, Camoletto S, Torrent MC. Estimación del contenido de hierro, ácido fólico, tiamina, riboflavina y niacina en alimentos elaborados con harina de trigo enriquecida. Rev Esp Nutr Comunitaria. 2010; 16(2):77-82. 